Egypt. J. of Appl. Sci., 35 (11) 2020

\title{
CD326 EVALUATION IN HEPATOCELLULAR CARCINOMA PATIENTS WITH AND WITHOUT PORTAL VEIN TUMOR THROMBOSIS
}

\author{
Mohamed Elshal $^{1}$; Mohamed Y. Nasr ${ }^{2}$; Mahmoud Gadallah ${ }^{3}$ \\ and Aya Nasser*4 \\ 1Professor of molecular biology, Department of biochemistry and molecular biology, \\ 2 Lecturer of Molecular Diagnosis, Molecular Diagnosis Department, Genetic \\ Genetic Engineering and Biotechnology Research Institute, Sadat University. Egypt. \\ Engineering and Biotechnology Research Institute, Sadat City University, Egypt. \\ 3 Lecturer of Molecular Diagnosis, Molecular Diagnosis Department, Genetic \\ Engineering and Biotechnology Research Institute, Sadat City University, Egypt. \\ 4 Master degree in Department of biochemistry and molecular biology, Genetic \\ Engineering and Biotechnology Research Institute, Sadat City University, Egypt \\ *01111710212 aya@gmail.com
}

Key Words: cluster of differentiation 326, circulating tumor cell, patient management, hepatocellular carcinoma, flow cytometry

\section{ABSTRACT.}

Aim : to evaluated the presence and clinical relevance of a cluster of differentiation (CD)326+subset of circulating tumor cells (CTCs) in blood samples of hepatocellular carcinoma patients with portal vein tumor thrombus and without portal vein tumor thrombosis, who had undergone curative or palliative intervention, in order to find a novel prognostic factor for patient management and follow-up.

Method: In total, $47 \mathrm{HCC}$ patients, along with 21 with PVTT and 26 without PVTT were included. The easily transferable methodology of flow cytometry, along with multiparametric antibody staining were used to selectively evaluate CD326+CTCs in the peripheral blood samples of HCC patients. The multiparametric selection allowed any enrichment methods to be avoided thus rendering the whole procedure suitable for clinical routine.

Result: The presence of CD326+ cells was strongly correlated with poor survival and high metastasis rates in this novel patient population as well as PVTT probability for CD $326>$ or $<0.45$ was $88.0 \%$. Several factors independently correlated with CD326 using univariate multiple logistic regression of CD 326 with laboratory parameters Correlation was found between EPCAM activity and AST, ALT, AFP at P Value less than 0.01 In conclusion: CD326+ CTCs are an independent prognostic factor for tumor aggressiveness rate in multivariate analysis, suggesting that their evaluation could be an additional factor for liver cancer progression risk evaluation in patient management 


\section{INTRODUCTION}

Hepatocellular carcinoma (HCC) is responsible for significant morbidity and mortality in cirrhosis and also accounts for between $85 \%$ and $90 \%$ of primary liver cancer ${ }^{[1-2]}$. Most of HCCs in the world occur in the setting of cirrhosis and over half-million of people develop liver cancer every year and an almost equal number die of $\mathrm{it}^{[3]}$. The most important causes leading to HCC are the HBV and HCV infections, heavy alcohol consumption, aflatoxin B1, age and gender (males are more susceptible than females), tobacco consumption, obesity associated with nonalcoholic fatty liver disease, and the increase of the Diabetes II mellitus (that rises the risk factor between 2 and 3), genetic hemochromatosis, primary biliary cirrhosis, and alpha1-antitrypsin deficiency and autoimmune hepatitis [4] .

Usually HCC develop during long process of inflammation and fibrosis eventually leading to cirrhosis ${ }^{[5 \rho}$, Portal vein tumour thrombosis is common complications of HCC that occur in approximately 10_40 /of HCC patient at time of diagnosis .although great improvement have been made in diagnosis of HCC with PVTT and treatment during the past few decades the long term survival of these patients remain unfavourable, due to high mortality. conventional prognostic marker for HCC alpha feto protein and tumor node metastasis, but their value varies between patients with this diseases ${ }^{[6]}$,therefore new method are needed to provide predictive information about existing metastasis and probability of early recurrence.

In the field of biology of tumors, some expressions have been coined for the different types of circulating cellular elements. The term circulating tumor cells (CTC) defines a small population of cancer cells that have escaped from the primary tumor into the body's circulatory system, and establish metastases in distant organs, The presence of CTC reflects the aggressiveness nature of a solid tumor. Many attempts have been made to develop assays that reliably detect and enumerate these cells. The clinical results obtained with such assays suggest that in some tumor types, CTC detection and identification can be used to estimate prognosis and may serve as an early marker to assess antitumor activity of treatment.

In addition, CTC can be used to predict progression-free survival and overall survival. CTC are an interesting source of biological information in order to understand dissemination, drug resistance and treatment-induced cell death[7-8] .

In HCC animal models showed that 10 to $10000 \mathrm{CTC}$ are capable to initiate new metastasis . Even after curative resection, the tumor recurrence rate remains high. [9]

Although CTC detection has been applied and well documented in different types of cancer, CTC detection is not routinely performed in HCC follow-up and remains in the experimental field. However ,HCC 
CTC detection might bring new interesting information of metastatic process might be used as diagnostic tool of early recurrence and mav allow a better patient selection for liver transplantation. [10] but there are a numher of nrohleme affect $C$ TC identification and enumeration. each method used for their detection has several drawbacks[11] The scarrity of CTC in nerinheral hlond camnles meanc that an enrichment step is often required prior to the analysis $[12]$, however, all methods uced to enrich CTre from hlond camnlec (i a filtration density gradient separation and magnetic isolation) exhibit a low purity grade ${ }^{[13}$

Also , major techniques used to identify CTCs (i.e., quantitative polymerase chain reaction and CellSearch system) are too expensive and time consuming to be predominantly used in the clinical routine ${ }^{[14]}$. In addition, nucleic acid-based methods are markedly affected by the presence of a huge number of contaminant cells inside peripheral blood samples ${ }^{[15]}$ while intact cell analysis by the use of specific markers is defective due to the lack of unambiguous specificities ${ }^{[16]}$; in fact several of the markers expressed by cancer cells are shared by leucocytes. Flow cytometry is a suitable technique to analyze CTCs , as it allows single cell analysis and permits the researcher to include or exclude doubtful origin populations and suspect objects from the analysis at any time following sample acquisition. The universally recognized markers of CTCs are the epithelial specificities, CD326 (EpCAM) and the cytokeratins , [17] however, recent findings have highlighted the complex nature of cancer cell dissemination, which involves deep cell changes, including the epithelial-to-mesenchymal (EMT) transition . The types of modifications that occur in the cell in such transitions are not univocally clarified; it has been demonstrated that cells reduce the epithelial characteristics as mesenchymal features appear, this transition appears to promote cancer cell dissemination [18]

In addition, it has been reported that intermediate phenotypes are observable in CTCs with the presence of epithelial and mesenchymal markers ${ }^{[19]}$. The assessment of biologically significant markers is likely to provide more clinically relevant information than simple enumeration ${ }^{[20]}$,so Recent work suggest using Flow cytometry to identify expression of CD326 as tumor marker in CTCs of hepatocellular carcinoma with PVTT compared to patient without PVTT 
for improvement standard cancer staging criteria and assessment risk at early stage.

\section{Recruitment of individuals}

Patients collected between January 2020 and March 2020 from HCC CLINIC, NATIONAL LIVER INSTITUTE, Menoufia university. Patients with diabetes were excluded from these studies. In total, 47 patients, consisting of 26 without portal vein tumor thrombus and 21 with portal vein tumor thrombus patients, were included. According to Magnetic resonance imaging and computerized tomography scan 9 HCC patients with patent portal vein and 17 HCC patients with distal portal vein. Furthermore, 21patients, including 16 patients with partial portal vein tumor thrombus In the remaining five patients with complete portal vein tumor thrombus.

The following clinicopathological parameters were recorded: Age, gender, blood transfusion, surgery .focal lesion number, ALT,AST, AFP

\section{The following was done for each patient:}

\section{1-Flowcytometric technique}

$10 \mathrm{ml}$ were withdrawn from $48 \mathrm{HCC}$ patient to measure the percentage of CD326+ cells using flowcytometric technique. These blood samples were separated by RBCs lysing buffer Then, the mononuclear cells were extracted. Using phosphate buffer solution (PBS), a process of washing the mononuclear cells is done twice by incubation for 7 minutes at room temperature and Centrifugation at $250 \mathrm{x}$ g for 7 minutes. After that, the staining process is done by adding (FITC which was conjugated with anti-CD 45 antibody, PE which was conjugated with anticd326 antibody) into appropriate amount of sediment. This system was placed in a dark place for 15 minutes at $37^{\circ} \mathrm{C}$; after which the cells were washed with PBS. Finally, the CD326+cells are measured by flowcytometry (Miltenyi Biotec, Germany).

2- Liver enzyme, were represented by measuring the level of AST, ALT, AFP by automated biochemistry Huma Star 300 SR German.

3- To assess infection with hepatitis $B$ virus and hepatitis $C$ virus were measured using a (Stat Fax-4200 USA) device, qualitatively and quantitatively, depending on the technique of immune absorption linked to the enzyme (ELISA).

4- Statistical analyses were performed by IBM ${ }^{\circledR}$ SPSS ${ }^{\circledR}$ Statistics software version All data are expressed as mean \pm standard deviation $(\mathrm{X} \pm \mathrm{SD})$. Comparisons were analyzed by ANOVA one-way analysis $\mathrm{A}$ value of $\mathrm{P}<0.05$ : significant, $\mathrm{P}<0.001$ : more significant. that was considered statically significant. ROC curve was done to determine the cutoff point, area under curve (AUC), sensitivity (Sn), specificity (Sp), 
positive predictive value (PPV) and negative predictive value (NPV) of presences of portal vein thrombosis.

Measure the diagnostic power of indirect scores which came in modern scientific journals according to the following equations:

1- AST: platelets ratio index (APRI) was calculated using Wais formula: (AST (upper limit of normal)/ALT (IU/L) $\times 100) /$ platelet count (platelets x 109/L) X 100 .

2- Fibrosis index (FI) was calculated using this formula as: 8.0-0.01 x platelet count $(\mathrm{x} 109 / \mathrm{L})-$ serum albumin $(\mathrm{g} / \mathrm{dl})$.

\section{RESULT}

Total of 50 patient were included in this study 3 patient were omitted because of missing data leaving 47 patients in final analysis 26 patient were HCC without PVTT. median age in all studied group (patent, dilated, partial and complete PVTT)(table 1)

$(60.0 \quad 5.38 \pm, 58.53 \quad 5.68 \pm, 6.66 \pm 60.19,6.34 \pm 65.40)$

Majority were male $\mathrm{n}=39$, and $44.6 \%$ had HCC with portal vein tumor thrombus, etiology of underlying liver cancer included ( $\mathrm{HCV} n$ $=46, \mathrm{HBV} \mathrm{n}=1$ ).

Table 1: Comparison between studied groups as regard Age and Gender

\begin{tabular}{|c|c|c|c|c|c|}
\hline Variables & Groups & $\underset{\mathbf{N}=9}{\text { Group1 }}$ & $\underset{\mathbf{N}=17}{\text { Group2 }}$ & $\begin{array}{c}\text { Group3 } \\
\mathbf{N}=16\end{array}$ & $\underset{\mathrm{N}=5}{\text { Group4 }}$ \\
\hline \multirow{2}{*}{ Gender } & Male & 99 & $\begin{array}{c}13 \\
76.5 \%\end{array}$ & $\begin{array}{c}14 \\
87.5 \%\end{array}$ & $\begin{array}{c}3 \\
60 \%\end{array}$ \\
\hline & Female & $\begin{array}{c}0 \\
0.00 \%\end{array}$ & $23.5 \%$ & $\stackrel{2}{12.5 \%}$ & $\begin{array}{c}2 \\
40.0 \% \\
\end{array}$ \\
\hline
\end{tabular}

Mean blood level of CD326 in 4 studied group was $(0.49 \pm 0.77,1.39 \pm$ $3.06,2.68 \pm 3.18,6.62 \pm 5.99$ )(table 2 ), the enzyme activities of ALT ,AST in partial portal vein tumor thrombus $[94.63 \pm 3.12,160.06 \pm 8.06]$ and complete PVTT patients $[99.40 \pm 0.89,181.40 \pm 5.77]$ were significant higher than in patient without PVTT. . In contrast, significant differences were found in AFP between (patent, dilated) versus (partial, complete) $(\mathrm{P}=0.000)$.

Table 1: Comparison between studied groups as regard Laboratory data

\begin{tabular}{|l|c|c|c|c|c|}
\hline Groups & $\begin{array}{c}\text { Group1 N=9 } \\
\text { Mean } \pm \text { SD }\end{array}$ & $\begin{array}{c}\text { Group2(N=17) } \\
\text { Mean } \pm \text { SD }\end{array}$ & $\begin{array}{c}\text { Group3(N=16) } \\
\text { Mean } \pm \text { SD }\end{array}$ & $\begin{array}{c}\text { Group4(N=5) } \\
\text { Mean } \pm \text { SD }\end{array}$ & p-value \\
\hline ALT (U/L) & $\mathbf{5 3 . 8 9} \pm \mathbf{5 . 0 7}$ & $\mathbf{6 3 . 7 5} \pm \mathbf{6 . 6 3}$ & $\mathbf{9 4 . 6 3} \pm \mathbf{3 . 1 2}$ & $\mathbf{9 9 . 4 0} \pm \mathbf{0 . 8 9}$ & $\mathbf{0 . 0 0 0}$ \\
\hline AST(U/L) & $\mathbf{1 0 4 . 6 7} \pm \mathbf{3 . 7 1}$ & $\mathbf{1 2 7 . 5 9} \pm \mathbf{8 . 6 5}$ & $\mathbf{1 6 0 . 0 6} \pm \mathbf{8 . 0 6}$ & $\mathbf{1 8 1 . 4 0} \pm \mathbf{5 . 7 7}$ & $\mathbf{0 . 0 0 0}$ \\
\hline AFP(ug/ml) & $\mathbf{1 1 . 8 9} \pm \mathbf{3 . 0 9}$ & $\mathbf{9 9 . 5 3} \pm \mathbf{1 2 3 . 3 8}$ & $\mathbf{5 0 3 . 6 9} \pm \mathbf{1 0 3 . 9 7}$ & $\mathbf{9 6 4 . 8 0} \pm \mathbf{1 4 5 . 5 2}$ & $\mathbf{0 . 0 0 0}$ \\
\hline Cd326 & $\mathbf{0 . 4 9} \pm \mathbf{0 . 7 7}$ & $\mathbf{1 . 3 9} \pm \mathbf{3 . 0 6}$ & $\mathbf{2 . 6 8} \pm \mathbf{3 . 1 8}$ & $\mathbf{6 . 6 2} \pm \mathbf{5 . 9 9}$ & $\mathbf{0 . 0 0 8}$ \\
\hline
\end{tabular}




\section{Correlation between CD326 and different variable are illustrated in} table 3

highly significant association was observed between EPCAM CD 326 and the AFP . furthermore liver enzyme ALT and AST were significant associated $\mathrm{P}<0.01$ with CD326 in all HCC patient included in this study .

Table 3: correlation between CD326 and liver function test

\begin{tabular}{|c|c|c|c|c|c|}
\hline \multirow[b]{2}{*}{ Variables } & \multicolumn{5}{|c|}{ Cd326 } \\
\hline & $\begin{array}{c}\text { patent PV } \\
\mathbf{N}=9\end{array}$ & $\begin{array}{c}\text { dilated PV } \\
(\mathbf{N}=17)\end{array}$ & $\begin{array}{l}\text { partial } \\
\text { PVTT } \\
(\mathrm{N}=16)\end{array}$ & $\begin{array}{c}\text { complete } \\
\text { PVTT } \\
(\mathrm{N}=5)\end{array}$ & $\begin{array}{c}\text { Total } \\
(\mathrm{N}=47)\end{array}$ \\
\hline ALT (U/L) & $0.670 *$ & $0.657 *$ & $0.761 * *$ & $0.936 *$ & $0.531 * *$ \\
\hline AST(U/L) & 0.779* & $0.577 *$ & $0.926 * *$ & 0.920* & $0.606 * *$ \\
\hline $\operatorname{AFP}(\mathrm{ng} / \mathrm{ml})$ & $0.770 *$ & $0.733 * *$ & $\mathbf{0 . 8 8 0} * *$ & $0.944 *$ & $0.687 * *$ \\
\hline
\end{tabular}

**: significant at $\mathbf{p}=0.01 *$ : significant at $\mathbf{p}=\mathbf{0 . . 0 5}$

The diagnostic abilities of CD326 versus those of APRI and FIB4 illustrated in table 4

Unfortunately, there are not significant correlation between CD326 and (APRI or FIB 4) among 4 studied group

\section{cytometric analysis for CD326}

A multiparametric cytometric analysis was used to evaluate the CD326+ CTCs present in the peripheral blood samples of the PVTT HCC patients and without PVTT HCC. The cells were first gated on physical parameters in a dot plot [forward scatter versus side scatter (SSC)] to exclude debris. Subsequently, in a CD45 versus SSC dot plot, the CD45cell population position was identified by discarding all hematopoietic contaminants. Finally, a CD326 dot plot, + CTCs were identified 'finally we calculated the cut point using the partial and complete PVTT groups together as positive HCC group ,patient without PVTT $(n=26)$ served as negative group .ROC analysis showed the best cut point at a sensitivity of about $81 \%, 88 \%$ for CD26 and CD 326 . The specificity and sensitivity values are as follows in fig 1 .

Table 4: correlation between CD326 and (APRI, FIB 4)

\begin{tabular}{|c|c|c|c|c|}
\hline & \multicolumn{4}{|c|}{ CD326 } \\
\hline Variables & $\begin{array}{c}\text { partial pv } \\
(\mathbf{N}=\mathbf{1 6})\end{array}$ & $\begin{array}{c}\text { dilated pv } \\
(\mathbf{N}=\mathbf{1 7})\end{array}$ & $\begin{array}{c}\text { patent pv } \\
\mathbf{N = 9}\end{array}$ & $\begin{array}{c}\text { complete pv } \\
(\mathbf{N}=\mathbf{5})\end{array}$ \\
\hline APRI SCORE & -0.41102 & -0.15308 & -0.18365 & -0.25981 \\
\hline FIB 4 SCORE & -0.20775 & -0.12181 & -0.15877 & -0.45762 \\
\hline
\end{tabular}

\section{DISCUSSION}

In the past few decades, many promising candidate biomarkers for $\mathrm{HCC}$ had been found, but most of them were not applied to clinical diagnosis due to their limited practicability and high cost . Nevertheless, these new markers have potential to be applied in clinical diagnosis for their higher sensitivity and specificity. So far, $\alpha$-fetoprotein (AFP) and imaging technology (e.g., ultrasound or computed tomography) are two primary methods to diagnose HCC in hospitals. 
AFP has been used as a serum marker for HCC for many years, but its sensitivity was only about $39 \%-65 \%$ [22]

Recently, we have identified epithelial cell adhesion molecule (EpCAM), to be an early biomarker of $\mathrm{HC}_{23} \mathrm{C}$ because its expression is highly elevated in premalignant hepatic tissues . EpCAM (also known as CO17-1A, EGP, EGP40, GA733-2, KSA, Ly74, M1S2, M4S1, MIC18, MK-1, TROP1, and hEGP-2) is highly expressed in many human cancers with an epithelial origin.

The function of EpCAM and the regulation of its expression are largely unknown $^{[24]}$. In the adult liver, hepatocytes are negative and bile duct epithelium is positive for EpCAM expression ${ }^{[25]}$. However, in the embryonic liver, the majority of hepatocytes express EpCAM . In the cirrhotic liver, EpCAM is expressed in proliferating bile ductulus that are thought to be derived from HPC [26] . but its distribution pattern is altered in hepatocellular carcinoma according to previous study published by Gi Hong Choi who examined mRNA levels for K19, EpCAM, and CD44 in peripheral blood and HCC tissues before and after operation using real-time RT-PCR. Study participants were divided into high and low ratio groups, according to the ratio of postoperative to preoperative mRNA levels for each marker.. . their Findings revealed that Preoperative peripheral levels of K19 and EpCAM mRNA were higher in liver transplantation patients than in resection patients, and they were also significantly higher in cirrhotic patients of Child-Pugh Class B or C than those of Child-Pugh Class A (p\0.05 for all).. Preoperative peripheral levels of K19 and EpCAM mRNA were influenced by background liver status and HCC. Additionally, the ratio of postoperative to preoperative mRNA levels for CSC markers, especially K19 and EPCAM, was shown to be important to predict $\mathrm{HCC}$ recurrence ${ }^{[27]}$.

Another study by Taro Yamashita who identified EpCAM-positive HCCs by cDNA microarray in $40 \mathrm{HCC}$ cases and validated by oligonucleotide microarray analysis of 238 independent HCC cases, which was further confirmed by immunohistochemical analysis of an additional 101 HCC cases. EpCAM-positive HCC displayed a distinct molecular signature with features of hepatic progenitor cells including the presence of known stem/progenitor markers such as cytokeratin 19, cKit, EpCAM, and activated Wnt-B-catenin signaling, whereas EpCAM-negative HCC displayed genes with features of mature hepatocytes. Moreover, EpCAMpositive and EpCAM-negative HCC could be further subclassified into four groups with prognostic implication by determining the level of A-fetoprotein (AFP). These four subtypes displayed distinct gene expression patterns with features resembling certain stages of hepatic lineages. Taken together, they proposed an easy classification system defined by EpCAM and AFP to reveal HCC subtypes similar to hepatic cell maturation lineages, which may enable prognostic stratification and assessment of HCC patients with adjuvant therapy and provide new insights into the potential cellular origin of HCC and its activated molecular pathways ${ }^{[28]}$.

These result once more underline the pathological role of CD326 in HCC Therefore, the current study selected EPCAM to explore the CTC populations in the 
peripheral blood of HCC patients by flow cytometry. Our goal was to validate the usefulness of the CD326 as diagnostic marker in progression liver cancer

Our cohort revealed that Portal vein tumor thrombosis patients of HCC had the highest number of CD326+ CTCs and Blood levels of CD326+CTCs correctly predicted tumor prognosis in $85,7 \%$ of the cases, by contrast, negative patient (patent , dilated) expressed decrease number of cd 326+ CTC in $84,4 \%$ of cases, with a test specificity of $88 \%$. (Fig 1).

Our second goal was to examine possible correlation between CD 326 activity and other laboratory parameters of liver function. We focused on 3 parameters that were associated with prognosis in HCC patients. included were markers of liver damage such as AST, ALT,. also included were AFP that were correlated with tumor aggressiveness.

Consistent with previous published data by UC Okonkwo et al who analyzed bilirubin, alanine aminotransferase (ALT), aspartate aminotransferase (AST), alkaline phosphatase (ALP) and albumin in 64 patients with HCC and 120 patients without HCC they observed that ., AST and ALT were elevated in 30(46.9\%) and 31(48.4\%) patients, respectively, while ALP was elevated in 33(52\%). Hyper bilirubinaemia was present in $34(53 \%)$ and hypo albuminaemia in 54(84.3\%) of the patients. Except for bilirubin, liver function test was more frequently abnormal in HCC than in non-HCC cases [29] This seems logical and in agreement with Our study which revealed highly significant difference among studied groups in liver enzyme (AST,ALT) at $\mathrm{P}<0.001$ and highly significant correlation with CD326 at $\mathrm{P}<0.001$

In present study we showed highly significant correlation between $\mathrm{Cd} 326$ and AFP, at $\mathrm{p}$ value $<0.01$ in total 47 patient, similar to our result Leonardo do Prado Lima, et al, (2018) concluded that. EpCAM+ expression was associated with AFP + $(\mathrm{OR}=12.5,95 \% \mathrm{CI}, 1.9-84.1, \mathrm{p}<0.001)$ in child Pugh A HCC patient undergoing curative surgical resection $[30]$.

As predicted in our study, HCC patients showed a positivity for CD326+ even when the primary cancer had a low pathological grade, suggesting that CTCs can identify high-risk HCC patients at early stages. Notably, the spread of CD326+ cancer cells into the blood circulation is a common event and $81 \%$ of all analyzed patients exhibited these cells in their peripheral blood (figure 1) we have also proven to be useful in detecting minor subgroups of cells present in the primary tissue which might eventually be the cause of treatment resistance or relapse of the disease.

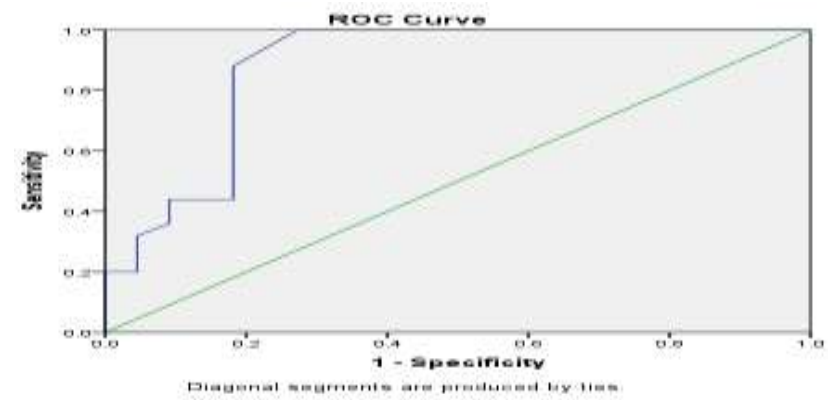

Fig 1: CD326 
ROC curve of CD326 between Patients group

\begin{tabular}{|c|c|c|c|c|c|c|c|}
\hline & Cut off & $\begin{array}{c}\text { Area } \\
\text { under } \\
\text { the } \\
\text { curve }\end{array}$ & Sensitivity & specificity & PPV & NPV & $\begin{array}{c}\text { P- } \\
\text { value }\end{array}$ \\
\hline CD326 & $>\mathbf{0 . 4 5}$ & $\mathbf{0 . 8 3 1}$ & $\mathbf{8 8 . 0}$ & $\mathbf{8 1 . 0}$ & $\mathbf{8 4 . 6}$ & $\mathbf{8 5 . 7}$ & $\mathbf{0 . 0 1}$ \\
\hline
\end{tabular}

\section{REFERENCES}

1. Sun, W. ; Q. Su ; X. Cao ; B. Shang ; A. Chen ; H. Yin and B. Liu (2014). High expression of polo-like kinase 1 is associated with early development of hepatocellular carcinoma. International journal of genomics, Volume 2014, Article ID 312130, 9 pages.

2. Tandon, P. and G. Garcia-Tsao (2009). Prognostic indicators in hepatocellular carcinoma: a systematic review of 72 studies. Liver International, 29(4): 502-510.

3. Hussain, K. and H.B. El-Serag, (2009). Epidemiology, screening, diagnosis and treatment of hepatocellular carcinoma. Minerva gastroenterologica e dietologica, 55(2): 123-138

4. Banks, E. ; G. Reeves ; V. Beral ; D. Bull ; B. Crossley ; M. Simmonds and R. English (2005). Hormone replacement therapy and false positive recall in the Million Women Study: patterns of use, hormonal constituents and consistency of effect. Breast Cancer Research, 8(1): R8

5. Idilman, R. ; N. De Maria ; A. Colantoni and D.H. Van Thiel (1998). Pathogenesis of hepatitis B and C-induced hepatocellular carcinoma. Journal of viral hepatitis, 5(5): 285-299

6. Mendizabal, Manuel and K. Rajender Reddy (2009): "Current management of hepatocellular carcinoma." Medical Clinics 93(4): 885-900.

7. Mocellin, S. ; D. Hoon ; A. Ambrosi ; D. Nitti and C.R. Rossi (2006). The prognostic value of circulating tumor cells in patients with melanoma: a systematic review and meta-analysis. Clinical cancer research, 12(15): 4605-4613

8. Mocellin, S. ; U. Keilholz ; C.R. Rossi and D. Nitti (2006). Circulating tumor cells: the 'leukemic phase'of solid cancers. Trends in molecular medicine, 12(3): 130-139

9. Groom, A.C. ; I.C. MacDonald; E.E. Schmidt ; V.L. Morris and A.F. Chambers (1999). Tumor metastasis to the liver, and the roles of proteinases and adhesion molecules: new concepts from in vivo videomicroscopy. Canadian Journal of Gastroenterology, 13(9):733-43. Aselmann, H. ; H. Wolfes ; F. Rohde ; M. Frerker ; A. Deiwick ; M.D. Jäger and H.J. Schlitt (2001). Quantification of $\alpha 1$-fetoprotein mRNA in peripheral blood and bone marrow: a tool for perioperative evaluation of patients with hepatocellular carcinoma. Langenbeck's Archives of Surgery, 386(2): 118-123.

10. Lianidou, E. S. and A. Markou (2011). Circulating tumor cells in breast cancer: detection systems, molecular characterization, and future challenges. Clinical chemistry, 57(9): 1242-1255. 
11. Alunni-Fabbroni, M. and M. T. Sandri (2010). Circulating tumour cells in clinical practice: Methods of detection and possible characterization. Methods, 50(4): 289-297

12. Königsberg, R. ; E. Obermayr ; G. Bises ; G. Pfeiler ; M. Gneist ; F. Wrba and C. Dittrich (2011). Detection of EpCAM positive and negative circulating tumor cells in metastatic breast cancer patients. Acta Oncological, 50(5): 700-710

13. Chiappini, F. (2012). Circulating tumor cells measurements in hepatocellular carcinoma. International journal of hepatology, Volume 2012, Article ID 684802, 16 pages

14. Wong, S.C.C. ; C.M.L. Chan; B.B.Y. Ma; E.P. Hui ; S.S.M.Ng ; San P.B. Lai and T.C.C. Au (2009). Clinical significance of cytokeratin 20positive circulating tumor cells detected by a refined immunomagnetic enrichment assay in colorectal cancer patients. Clinical Cancer Research, 15(3): 1005-1012

15. Parkinson, D.R. ; N. Dracopoli; B.G. Petty; C. Compton; M. Cristofanilli; A. Deisseroth and M.C. Liu (2012). Considerations in the development of circulating tumor cell technology for clinical use. Journal of translational medicine, 10(1): 138

16. Anja van de Stolpe, A.; K. Pantel ; S. Sleịfer ; L.W. Terstappen and Den J.M.Toonder (2011). Circulating Tumor Cell Isolation and Diagnostics: Toward Routine Clinical Use. Cancer Res; 71(18): 5955-5960

17. Armstrong, A.J. ; M.S. Marengo ; S. Oltean ; G. Kemeny ; R.L.Bitting ; J.D. Turnbull and M.A. Garcia-Blanco (2011). Circulating tumor cells from patients with advanced prostate and breast cancer display both epithelial and mesenchymal markers. Molecular cancer research, 9(8): 997-1007

18. Aceto, N. ; A. Bardia ; D.T. Miyamoto ; M.C. Donaldson ; B.S. Wittner ; J.A. Spencer and B.W. Brannigan (2014). Circulating tumor cell clusters are oligoclonal precursors of breast cancer metastasis. Cell, 158(5): 1110-1122.

19. Budd, G. T. (2009). Let me do more than count the ways: what circulating tumor cells can tell us about the biology of cancer. Molecular pharmaceutics, 6(5): 1307-1310.

20. Daniele, B. ; A. Bencivenga ; A.S. Megna and V. Tinessa (2004). $\alpha$ fetoprotein and ultrasonography screening for hepatocellular carcinoma. Gastroenterology, 127(5): S108-S112.

21. Kim, J. W.; Q. Ye ; M. Forgues ; Y. Chen ; A. Budhu ; J. Sime and X.W. Wang (2004). Cancer-associated molecular signature in the tissue samples of patients with cirrhosis. Hepatology, 39(2): 518-527.

22. Herlyn, M. ; Z. Steplewski; D. Herlyn and H. Koprowski (1979). Colorectal carcinoma-specific antigen: detection by means of monoclonal antibodies. Proceedings of the National Academy of Sciences,76(3):14381442.

23. Winter, M.J. ; B. Nagelkerken ; A.E. Mertens ; H.A. Rees-Bakker ; I.H. Briaire-de Bruijn and S.V. Litvinov (2003). Expression of Ep-CAM 
shifts the state of cadherin-mediated adhesions from strong to weak. Experimental cell research, 285(1): 50-58.

24. de Boer, C.J.; J.H. van Krieken; C.M.Janssen-van Rhijn and S.V. Litvinov(1999). Expression of Ep-CAM in normal, regenerating, metaplastic, and neoplastic liver. The Journal of pathology, 188(2): 201-206.

25. Choi, G. H. ; G.I. Kim ; J.E. Yoo ; D.C. Na ; Y.H. Roh ; Y.N. Park and J. S. Choi (2015). Increased expression of circulating cancer stem cell markers during the perioperative period predicts early recurrence after curative resection of hepatocellular carcinoma. Annals of surgical oncology, 22(3): 1444-1452

26. Yamashita, T. ; M. Forgues ; W. Wang ; J.W. Kim ; Q. Ye ; H. Jia and Z. Y. Tang (2008). EpCAM and $\alpha$-fetoprotein expression defines novel prognostic subtypes of hepatocellular carcinoma. Cancer research, 68(5): 1451-1461..

27. Lopez, J. B. ; M. Balasegaram ; V. Thambyrajah and J. Timor (1996). The value of liver function tests in hepatocellular carcinoma. Malaysian Journal of Pathology, 18: 95-100.

28. Lima, L.D.P. ; C.J. Machado ; J.B.S.R. Rodrigues ; L.D.S. Vasconcellos, ; E.P. Junior ; P.V.T. Vidigal and V. Resende (2018). Immunohistochemical Coexpression of Epithelial Cell Adhesion Molecule and Alpha-Fetoprotein in Hepatocellular Carcinoma. Canadian Journal of Gastroenterology and Hepatology, Volume 2018, Article ID 5970852, 8 pages. 
لكي تستوطن في عضو اخر وكونت مايسمي بالانبتاث و هذه الخلايا مسؤلة عن تطور المرض ولهذا ولائا

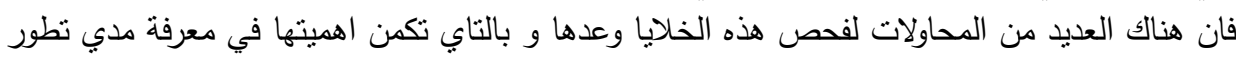

هناك العديد من النتنيات التي استخدمت لعد الخلايا السرطانية مثل جهاز

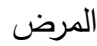
search system و لكن تكلفتها عالية و مهدرة للوقت و لكن الإبحاث التياث الجديدة اثتبت فعالية جهاز التدفف الخلوي فهو يقوم بعد خلية خلية و يقوم باستئصال الخلية المشكوكة فيه لاليه ولهذا فان بحثا يقوم بعد الخلايا السرطانية الموجودة في سرطان الكبد عن طريق عد CD326 او EPCAM الموجود علي اسطح الخلايا المرضى الذين استخدما في الدراسة جمعت بين كانون الثاني / يناير 2020 آذار / مارس عام الديا

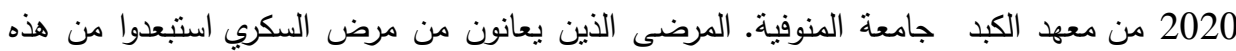

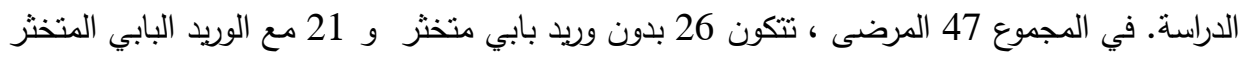

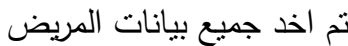

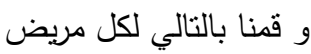
1 - تحليل وظائف الكيد 2- فياس نسبة CD326 الموجود علي الخلايا السرطانية

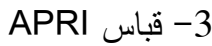

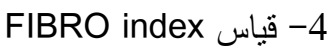
5- 5 التحاليل الاحصائية

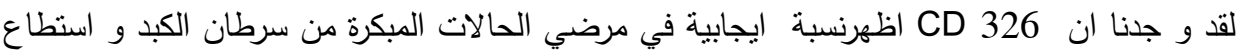

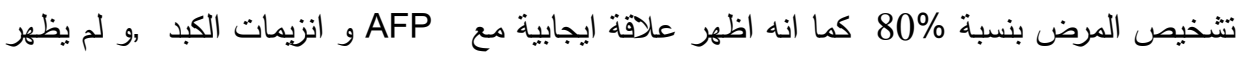
اي علاقة مع العرضع 